\title{
Consumo de pescado e outros alimentos pela população indígena da aldeia Mapuera, Oriximiná, Pará
}

\section{Consumption of fish and other foods by the indigenous population of aldeia Mapuera, Oriximiná, Pará}

\section{Tanimsom komo kitkmo anarî komo tahsom komo mero tooto komo Mapuera pono komo Oriximiná Pará}

\author{
Alex Isaac Wai-Wai da Silva ${ }^{1}$ \\ Charles Hanry Faria Junior ${ }^{2}$
}

\begin{abstract}
Resumo: $O$ estudo foi realizado na Aldeia Mapuera, Terra Indígena Trombetas, Oriximiná - Pará no ano de 2016 mediante entrevistas realizadas com 32 chefes de famílias, abrangendo 155 habitantes, para diagnosticar o consumo de pescado e outros itens alimentares pela população Indígena. Os dados foram analisados com técnicas da estatística descritiva e regressão linear simples para apresentar o efeito do número de pessoas na família sobre o consumo per capita de alimentos por período sazonal. Foi observada uma divisão nas tarefas entre homens e mulheres, onde os filhos se inserem de acordo com sua faixa etária e gênero, sendo assim o conhecimento repassado entre gerações. A agricultura, coleta de frutos e sementes, caça e pesca provêm o alimento consumido, que tem nível de consumo diferenciado entre os períodos de inverno e verão. Os Wai-Wai utilizam 30 etnoespécies de peixes, uma de crustáceos, uma de quelônios e uma de crocodilianos, capturados com o auxílio de 10 aparelhos de captura, além de diversificados itens derivados da agricultura, coleta e caça. Para o universo amostral, o quantitativo estimado de pescado consumido no período de inverno foi de $10.874,40 \mathrm{~kg}$ e de $7.984,14 \mathrm{~kg}$ no verão, para os produtos derivados da agricultura e coleta de $9.834,14 \mathrm{~kg}$ no inverno e 20.776,06 kg no verão, permitindo estimar que a demanda anual total dos habitantes da Aldeia Mapuera é da ordem de 105.198,48 kg de pescado e 171.170,40 kg de alimentos de origem agrícola e coleta. Apesar desses quantitativos, foi observada uma tendência de menor quantitativo consumido por pessoa para núcleos familiares maiores, e observados relatos de redução de recurso naturais, tendo como motivador o aumento do número de pessoas na aldeia, o que merece investigação para auxiliar no uso sustentável dos recursos naturais e a manutenção do modo de vida e tradição da população Wai-Wai.
\end{abstract}

Palavras-chave: Consumo, Pescado, Wai-Wai, Pará.

Abstract: The study was carried out in Aldeia Mapuera, Trombetas Indigenous Land, Oriximiná - Para in the year 2016 through interviews with 32 heads of families, covering 155 inhabitants, to diagnose the consumption of fish and other

\footnotetext{
${ }^{1}$ Indígena da Aldeia Mapuera, acadêmico do Curso de Bacharelado Interdisciplinar em Ciências e Tecnologia das Águas - BICTA, Instituto de Ciências e Tecnologia das Águas - ICTA / Universidade Federal do Oeste do Pará - UFOPA. E-mail: alex23waiwai@gmail.com

${ }^{2}$ outor, docente do Curso de Bacharelado em Engenharia de Pesca - BEP e do BICTA/ICTA/UFOPA. E-Mail: chralesufopa@gmail.com / charleshanry@yahoo.com.br
} 
food items by the Indigenous population. Data were analyzed using descriptive statistics and simple linear regression techniques to show the effect of the number of people in the family on the per capita consumption of food per seasonal period. There was a division in the tasks between men and women, where the children are inserted according to their age group and gender, being the knowledge transferred between generations. Agriculture, harvesting of fruits and seeds, hunting and fishing provide the food consumed, which has a level of consumption differentiated between the periods of winter and summer. The Wai-Wai use 30 ethnospecies of fish, one of crustaceans, one of chelonians and one of crocodilians, captured with the aid of 10 capture devices, besides diversified items derived from agriculture, collection and hunting. For the sample universe, the estimated amount of fish consumed in the winter period was $10,874.40 \mathrm{~kg}$ and $7,984.14 \mathrm{~kg}$ in the summer, for the products derived from agriculture and $9,834.14 \mathrm{~kg}$ in winter and $20,776.06 \mathrm{~kg}$ in the summer, allowing to estimate that the total annual demand of the inhabitants of Aldeia Mapuera is of the order of $105,198.48 \mathrm{~kg}$ of fish and $171,170.40 \mathrm{~kg}$ of food of agricultural origin and collection. In spite of these quantitative variables, a trend of lower quantitative consumption per person was observed for larger families, and there were reports of reduction of natural resources, motivated by the increase in the number of people in the village, which deserves research to assist in the sustainable use of natural resources and maintaining the Wai-Wai way of life and tradition.

Keywords: Consumption, Fish, Wai-Wai, Pará.

Mewrexapu yai touxapu: ehcampoka tho po nêrhxe aldeia mapuera pona, índio komo rowon pona Trombetas Oriximiná Pará pona 2016 cimnipupo eronhîrî entano wire 32 tooto yepamrî komo, inare epamrî komo nai 155 yakenon, yîhyai so wencenhe ahcewai komo erewsî mahyatu wooto komo poko mero totó komo ya. Eronhîri on yipu komo poko entano wiranhe tooto yepamrî komo poko pataw makî wikenhe erewsî yahtopo poko woto tonotopo poko marha cimnipu yimaw no poko marha. Ero yimaw entano komo wire etapicikacho yiraconkatopo poko kîrî, woxam komo mero, tîmxikrî komo yihcampokokatopo yîmrenayiro. Mararî poko, nati yîhkatopo poko yathîrî, esetakatopo poko anîmtopo poko mero erwsî yahtopo poko, erewsîmko yahtopo katpan yîmaw no cimnipu cew tahsom komo mero. Wai Wai komo nahrî me cehsom nai kitkmo 30 yakenon, cewnhe marha xakawa,ceunhe kwaci, watwa komo mero, 10 yakeno nayi onwicano komo wotopo, animtopo marha, natî citopo, esetakatopo komo mero. Woto komo yanîmtopo poko enpotopo cimnipu po nehxe 10.874,40 yawsîn $(\mathrm{kg})$ katpan po nai natî komo yîyamtopo potutopo mero nayi 9.834,14 yawsîn $(\mathrm{kg})$ cimnipu po xa hara nayi 20.776,06 yawsîn $(\mathrm{kg})$ katpan po hara, ahnoro nai totó komo mapuera pono komo nahrî nayi wooto tonosom komo 105.198,48 yawsîn $(\mathrm{kg})$ nai marha ereusî komo tahsom mararî pono 171.170,40 yawsîn $(\mathrm{kg})$. On yipu komo yakenon, cemsomme nehxi tpoyeno komo yakro esereskmatopo komo poko wahra so nhe animtopo poko ceunhe so nhe animtopo poko, enatira nhe ehtome otimko komo, tooto komo yepamri ke mero ewto po, eroke panatanmepore nasi, cekaimapore marha nasî comota poko kehtopo koo yihcamnopura ehtopo poko kiuyam wai wai komo.

Tapota - yîhcitopo: knahrî, Tanînsom, Wai-Wai, Pará. 


\section{Introdução}

A pesca na Amazônia desempenha historicamente um papel de grande importância social, cultural e econômica, com primeiros registros em populações indígenas no período anterior à colonização portuguesa, portanto, uma das atividades produtiva mais antigas da região (VERÍSSIMO, 1895; SMITH, 1979; GOULDING, 1983; LOPES et al., 2015; COELHO et al., 2017; BRELAZ et al., 2018; SILVA e FERREIRA, 2018).

Para as comunidades indígenas amazônicas tradicionalmente dependentes da alimentação natural, a pesca é uma atividade de subsistência, onde o peixe constitui a base da proteína consumida ao longo de quase todo o ano (VAN VELTHEM, 1990; BRABO et al., 1999; MURRIETA, 2001; PIROSKI et al., 2003; SANTOS et al., 2003; ADMS et al., 2005; LEITE, 2007; PEZZUTI e CHAVES 2009; GARNELO et al., 2010; JUNIOR et al., 2015; COIMBRA et al., 2017; OVIEDO, 2017).

Nas aldeias indígenas localizadas no estado do Pará, estudos descrevem o elevado consumo de peixe em decorrência da falta de alternativas alimentares (BRABO et al., 1999). No contexto cultural, mesmo dependentes da proteína derivada do pescado, algumas espécies de peixes são evitados por terem a carne extremamente mole, como o poraquê (Electrophorus electricus), evitados pelos jovens indígenas para não envelhecerem rapidamente (ao consumir podem ficar com carnes flácidas como os velhos) ou o consumo de espécies causarem problemas de saúde para pessoas com feridas, hemorragia ou de resguardo (VAN VELTHEM, 1990). No contexto científico, podem também estar sujeitos a ocorrência de doenças associadas a contaminação por mercúrio, devido a dependência do consumo de peixes, como o observado no estado do Pará e Mato Grosso (BIDONE et al., 1995; KURO, 2003; SÁ et al., 2006).

Além da pesca, a profunda ligação com o uso comum dos recursos naturais permite a coleta de frutos silvestres, palmitos e insetos, que somados a proteína animal obtida com a caça e os produtos agrícolas das roças familiares provêm diversificados itens alimentares presentes na dieta das comunidades indígenas (MILLER et al., 1989; RIBEIRO, 1995; LEITE, 2007; KATZ, 2008; SCHULER , 2010; SILVA, 2015).

$\mathrm{Na}$ aldeia Mapuera, a pesca a caça, a coleta e a agricultura de subsistência mantêm um modo de vida tradicional praticado a séculos como um meio de sobrevivência 
dos povos Wai-Wai, assim como o observado para outros povos indígenas amazônicos (MILLER et al., 1989; PIROSKI et al., 2003; LEITE, 2007; KATZ, 2008; SCHULER ZEA, 2010), adaptados ao efeito do clima Amazônico, onde a disponibilidade e a utilização dos recursos naturais, bem como do uso do solo para a agricultura seguem um ciclo anual que se alterna entre a época seca, com baixo índice de precipitação, conhecida como verão, e a época chuvosa, de grande volume de chuvas, conhecida como inverno (MURRIETA, 2001; ADMS et al., 2005; LEITE, 2007; SCHULER ZEA, 2010).

De acordo com Cardoso e Junior (2012), na região da terra indígena NhamundáMapuera (onde se localiza a Aldeia Mapuera), os dados pluviométricos registrados na estação de Óbidos/PA caracterizam a estação seca de julho a setembro, com o início de precipitações em dezembro e meses de estação chuvosa de janeiro a maio. Nesse ciclo anual, o verão é considerado uma estação farta em comida e o inverno marcado pelos recursos mais escassos (LEITE, 2007; SCHULER ZEA, 2010).

Além da influência do clima sobre a disponibilidade dos recursos naturais, relatos (vivenciados pelo autor, acadêmico indigna da Universidade Federal do Oeste do Pará - UFOPA) apontam que os moradores da aldeia Mapuera vêm percebendo a diminuição da captura de algumas espécies de peixes como o jandiá (Rhamdia sebae), surubim (Pseudoplatystoma spp.), curimatã (Prochilodus nigricans) e peixe cachorro (Rhaphiodon vulpinus), bem como a captura de animais silvestres utilizados como caça nas proximidades da Aldeia Mapuera nos últimos anos, como resultado do aumento do número de pessoas residindo na aldeia, fato já descrito por Cardozo e Junior (2012).

Dessa forma, entender a dependência da população indígena do consumo de pescado é outros itens alimentares é de extrema importância, pois de acordo com Canesqui e Garcia (2005), a alimentação é imprescindível para a vida e a sobrevivência humana, por ser uma necessidade básica e vital. Nessa linha, o presente estudo apresenta o consumo de pescado e outras fontes alimentares utilizados pela população indígena da Aldeia Mapuera, para contribuir com o conhecimento sobre a realidade alimentar da população indígena, apresentar informações que possibilitem entender o grau de dependência do consumo de pescado e outras fontes alimentares, bem como entender seus hábitos e formas de exploração dos recursos naturais. 


\section{Materiais e Métodos}

A Terra Indígena Trombetas - Mapuera se localiza no município de Oriximiná, no Oeste do Pará, Norte do território Brasileiro (041’52.94"S / 5758'25.45"O) (Figura 1). Abriga 11 aldeias, entre elas a Aldeia Mapuera, escolhida por ser a mais antiga e mais povoada, onde habitam aproximadamente 2.000 pessoas (relato do coautor).

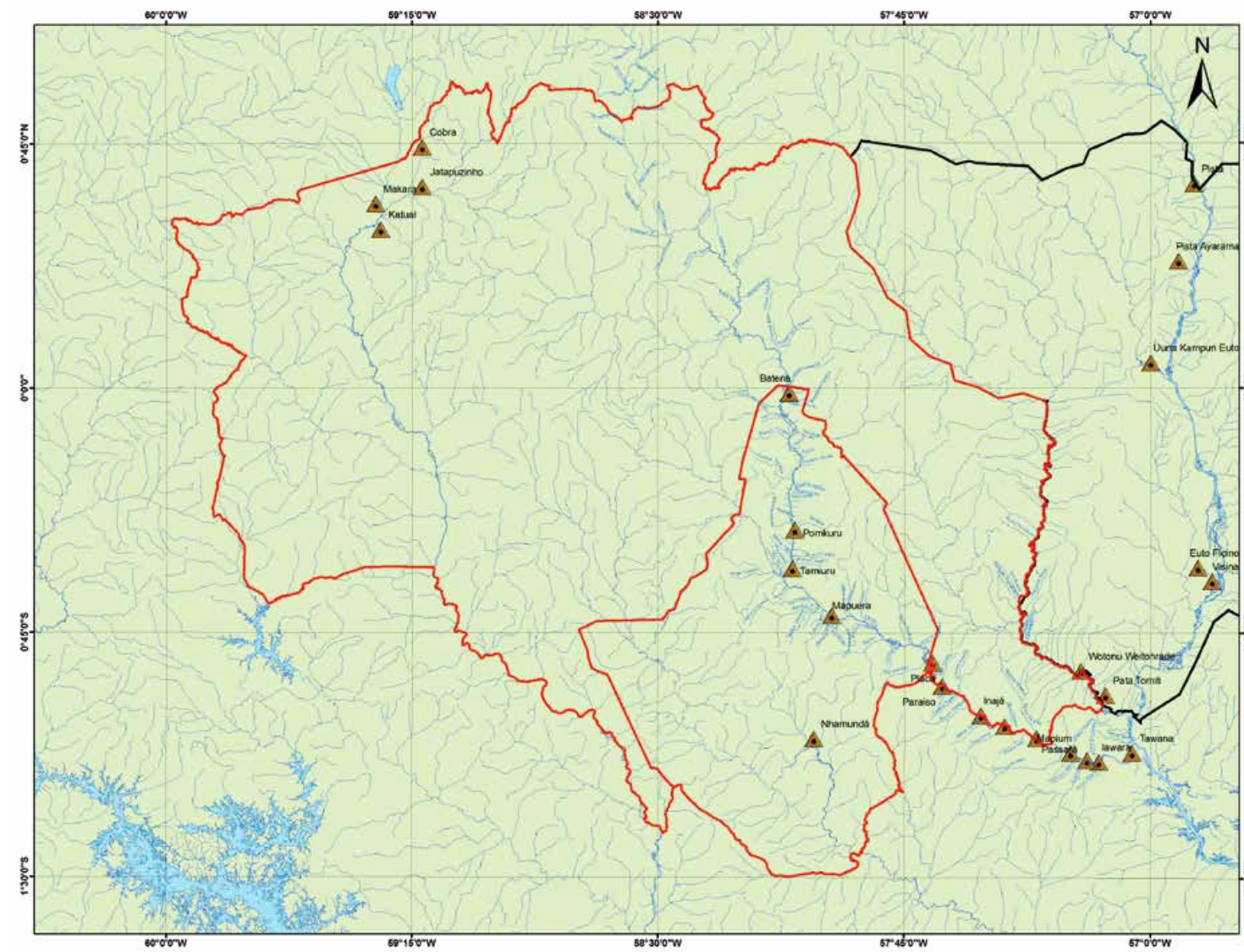

Figura 1. Mapa de localização da Aldeia Mapuera. Fone: Cardoso e Junior (2012).

A coleta de dados do consumo de pescado e outras fontes alimentares foi realizada com base na aplicação de formulários semi-estruturados para os chefes de famílias (unidade doméstica) e lideranças locais (indivíduo) (MURRIETA, 2001), de forma aleatória, de acordo com a disponibilidade em participar da entrevista.

A aplicação dos formulários foi realizada diretamente pelo discente indígena da UFOPA, de origem e família na região de estudo e coautor do trabalho. As coletas em campo foram realizadas durante os períodos de recesso das atividades acadêmicas da UFOPA no ano de 2016, quando foram realizadas duas excursões a área de estudo que totalizaram 45 dias. As entrevistas demandaram um tempo que variou entre 10 a 30 
minutos de acordo com a dinâmica das famílias indígenas visitadas, havendo em alguns casos a necessidade de retorno no dia seguinte para dar continuidade a coleta, para não comprometer as atividades tradicionais das famílias entrevistadas.

Entre as informações coletadas constam: idade e quantitativo de pessoas do núcleo familiar residindo na mesma casa, quantidade de pessoas na família que pescam, caçam ou trabalham na agricultura e coleta, aparelhos de pesca empregados, denominação e quantidade de peixes e outros itens alimentares produzidos ou coletados e o efeito da variação sazonal sobre o consumo ao longo do ano.

Os dados coletados foram armazenados na Plataforma Access e analisados mediante o emprego de ferramentas da estatística descritiva (gráficos, medidas descritivas e tabelas). Análises de regressão linear simples foram empregadas para relacionar a quantidade per capita de pescado e outros itens alimentares consumidos (variável dependente) em função do número de pessoas na família (variável independente) por período sazonal (ZAR, 1999).

\section{Resultados}

Registros históricos datam que o primeiro contato com o povo Wai-Wai da região do Alto Trombetas ocorreu no ano de 1947, no território da Guiana Inglesa, realizado por uma missão protestante Norte Americana com a finalidade de levar socorro médico, educar e evangelizar os indígenas (ISA, 1991), além da implantação da Unenvangelized Field Mission - UFM (Cruzada de Evangelização Mundial) e o trabalho conjunto com a Missão Evangélica da Amazônia - MEVA (EVELYN, 2010).

No território brasileiro, oficialmente os Wai-Wai se dispersam em três Terras Indígenas com alcance nos estados do Amazonas, Pará e Roraima: Terra Indígenas (TI) Nhamundá-Mapuera (AM/PA) com área de 1.049.520 ha, TI Trombetas/Mapuera (AM/RR/PA) com 3.970.420 ha e a TI Wai-Wai (RR) com 405.698 ha (EVELYN, 2010; CARDOZO e JUNIOR 2012; NEVES, 2014; ROCCO, 2014).

Nas áreas Nhamundá-Mapuera e Trombetas-Mapuera, a população foi estimada em 2.600 habitantes (ROCCO, 2014). Na Aldeia Mapuera, maior da Região, de acordo com dados coletados por Cardozo e Junior (2012) junto ao Cadastro de Pessoas Vivas 
Tabela 1. Composição percentual dos integrantes dos núcleos familiares.

\begin{tabular}{l|l|l|l}
\hline Gênero & Adulto (>14 anos) & Criança (até 13 anos) & Geral \\
\hline Feminino & $33,55 \%$ & $18,70 \%$ & $52,25 \%$ \\
\hline Masculino & $33,55 \%$ & $14,20 \%$ & $47,75 \%$ \\
\hline Total & $67,10 \%$ & $32,90 \%$ & $100,00 \%$ \\
\hline
\end{tabular}

Fonte: Alex Isaac Wai-Wai da Silva e Charles Hanry Faria Junior

Tabela 2. Amplitude e média de pessoas do núcleo familiar envolvidos nas atividades de subsistência.

\begin{tabular}{l|l|l}
\hline Atividades & Amplitude & Média \\
\hline Pesca & $1-5$ & $2,07 \pm 1,15$ \\
\hline Caça & $1-5$ & $2,11 \pm 0,68$ \\
\hline Agricultura e coleta de alimentos & $2-8$ & $3,52 \pm 1,43$ \\
\hline
\end{tabular}

Fonte: Alex Isaac Wai-Wai da Silva e Charles Hanry Faria Junior

- CPV do Posto de Saúde da FUNASA/Oriximiná em 2011, residiam no período 209 famílias e 977 habitantes.

No presente estudo foram visitadas 32 famílias residentes na Aldeia Mapuera, totalizando 155 pessoas, com amplitude de 2 a 10 pessoas por núcleo familiar e média de $5,14 \pm 1,98$ pessoas por residência, onde a composição dos núcleos familiares predomina os adultos e o gênero feminino (Tabela 1).

Entre as atividades de subsistência desenvolvidas pelos componentes dos núcleos familiares, a pesca possui a menor média de participação (Tabela 2), enquanto o plantio (agricultura familiar) e a coleta de alimento envolvem um maior número de integrantes entre as famílias estudadas.

Entre os produtos consumidos, derivados do cultivo, coleta e troca entre famílias, foram mencionados 40 itens, onde os 10 principais representam $80,2 \%$ do consumo total, ocorrendo diferenças entre os períodos sazonais (Tabela 3, Figura 2).

Entre os principais produtos da caça relacionados constam: anta, veado, porco do mato, macaco (coatá, guariba, prego), mutum, cutia, paca, tatu, jabuti, tucano e arara (Tabela 4, Figura 3), utilizados durante todo o ano de acordo com a necessidade da família e o sucesso na caça. O jabuti é encontrado durante os percursos para a roça ou pescarias e assim, são coletados para consumo. Entretanto, a quantificação desses itens não foi possível estabelecer devido à baixa quantidade dos dados informados.

$\mathrm{Na}$ ótica da pesca, apesar de mencionada como atividades de subsistência que 
Tabela 3. Lista de itens alimentícios derivados do cultivo ou coleta por período sazonal.

\begin{tabular}{l|l|l|l|l|l}
\hline Itens & Língua nativa & Nome científico & Inverno & Verão & Ano \\
\hline Abacaxí & Apara & Ananas spp. & & 7,3 & 4,6 \\
\hline Banana & Tuxkma & Musa spp. & 5,5 & 10,5 & 8,6 \\
\hline Batata & Paari & Solanum tuberosum & 10,1 & 8,8 & 9,3 \\
\hline Beijú & Cuure & & 25,5 & 10,2 & 15,9 \\
\hline Cará & Napí & Dioscorea sp. & 2,4 & 13,1 & 9,1 \\
\hline Farinha & Uuwi & & 16,6 & 7,8 & 11,1 \\
\hline Macaxeira & Makaxira & Manihot esculenta & 4,4 & 6,1 & 5,5 \\
\hline Tapioca & Yukwari & & 8 & 3,1 & 4,9 \\
\hline Vinho de bacaba & Kumu yukun & Oenocarpus multicaulis & 5,7 & 6,3 & 6,1 \\
\hline Vinho de burití & Yoowu & Mauritia flexuosa & 8,1 & 3,4 & 5,1 \\
\hline
\end{tabular}

Fonte: Alex Isaac Wai-Wai da Silva e Charles Hanry Faria Junior

Tabela 4. Caça utilizada como alimento pelos Wai-Wai.

\begin{tabular}{l|l|l|l|l|l}
\hline Item & Taxa & Língua nativa & Item & Taxa & $\begin{array}{l}\text { Língua na- } \\
\text { tiva }\end{array}$ \\
\hline Anta & Tapirusterrestris & Yaypi & Mutum & Crax globulosa & Pawxi \\
\hline Arara & Psitaciformes & Kworo & Nambu & Tinamus & Potwo \\
\hline Caititu & Pecari tajacu & Pakra & Paca & Agouti paca & Wirã \\
\hline Capivara & $\begin{array}{l}\text { Hydrochoerus hy- } \\
\text { drochaeris }\end{array}$ & Yiwiri & Papagaio & Psittacidae & Waru \\
\hline Cutia & Dasyprocta spp. & Akri & Porco do mato & Tayassu pecari & Ponko \\
\hline Jabuti & TESTUDINIDAE & Wayamu & Tatu & Dasypodidae & Kapayu \\
\hline Jacaré & Alligatoridae & Watwa & Tucano & Ramphastidae & Yakwe \\
\hline Macacos & Primates & Meku & Veado & $\begin{array}{l}\text { Mazama nemori- } \\
\text { vaga }\end{array}$ & Koso \\
\hline
\end{tabular}

Fonte: Alex Isaac Wai-Wai da Silva e Charles Hanry Faria Junior 


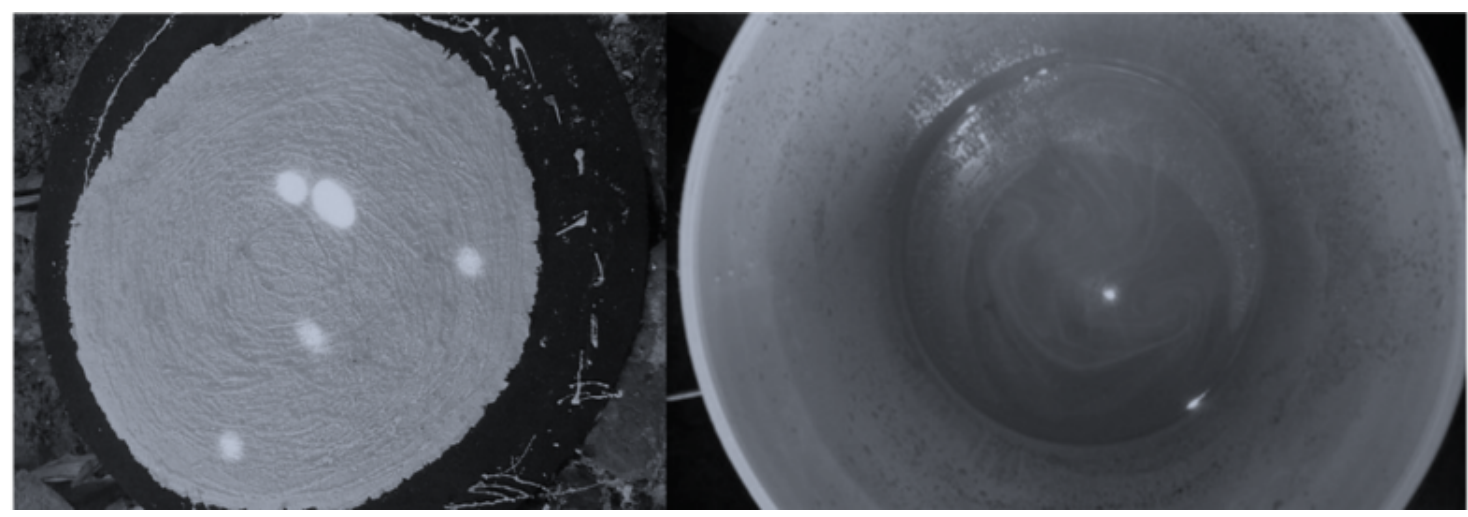

Figura 2. Alimentos produzidos a base dos produtos cultivados e coletados pelos Wai-Wai (beiju e vinho de bacaba respectivamente). Fonte: Alex Isaac Wai-Wai da Silva.

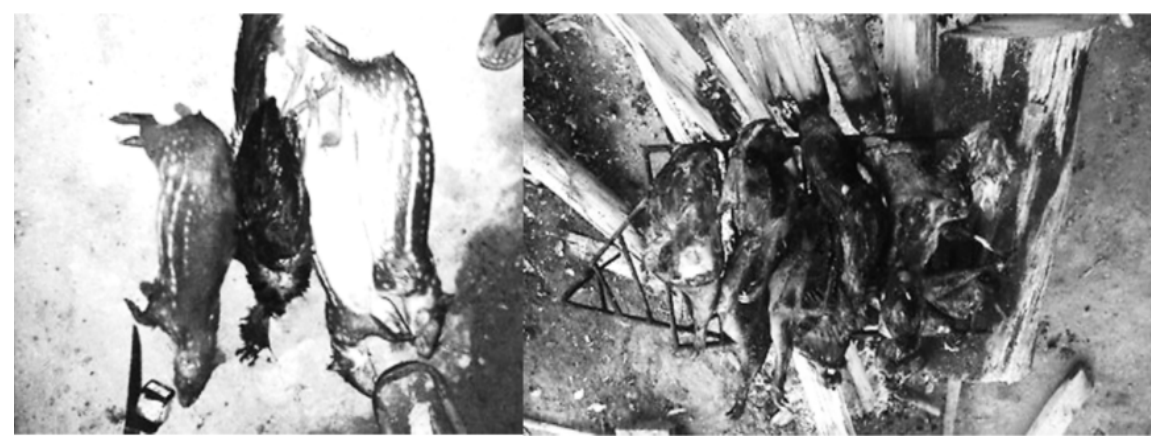

Figura 3. Imagem de caça utilizada pelos Wai-Wai. Fonte: Alex Isaac Wai-Wai da Silva

envolve o menor quantitativo de integrantes do núcleo familiar, é predominantemente realizada em parceria $(68,75 \%$ dos entrevistados), onde os participantes podem ser ou não do mesmo núcleo familiar e onde a mulher do entrevistado aparece como principal parceiro na atividade (Figura 4).

A amplitude de experiência de pesca dos entrevistados vai de 5 a 40 anos, com média de 26,24 \pm 10,55 anos. Exploram 30 etnoespécies de peixes (Tabela 5, Figura 5), uma de crustáceos, uma de quelônios e uma de crocodilianos, com percentual de captura diferenciado entre os períodos de inverno e verão.

A diferença no consumo de peixes entre os períodos sazonais resulta da maior dificuldade de captura de algumas etnoespécies, porém, baseados no comportamento dos peixes vivenciado ao logo da prática pesqueira e o compartilhamento do conhecimento dos pescadores Wai-Wai mais antigos e experientes, as dificuldades dão contornadas, como o observado nos relatos:

- No inverno as áreas com águas se expandem devido a subida das águas e os peixes se 
Tabela 5. Etnoespécies de peixes, crustáceos, quelônios e crocodilianos utilizadas.

\begin{tabular}{|c|c|c|c|c|}
\hline \multicolumn{3}{|c|}{ DENOMINAÇÃO } & \multicolumn{2}{|c|}{$\%$} \\
\hline Nome vulgar & Nome Científico & Língua nativa & Inverno & Verão \\
\hline Acari & Ancistrus sp. & Poré-citpiwem & 0 & 3,8 \\
\hline Aracu & Anostomidae & Kutisi & 1,6 & 1 \\
\hline Aracu flamengo & Leporinus fasciatus & Pkra Ktimon & 0,1 & 0,1 \\
\hline Arraia & Potamotrigonidae & Xpari & 1,8 & 0,5 \\
\hline Cara azul & Geophagus proximus & Tirpo & 0,2 & 2,3 \\
\hline Caranguejo & Pleocyemata & Xakawa & 0 & 0,1 \\
\hline Curimatã & Prochilodus nigricans & Kururir (Poso) & 5 & 4,7 \\
\hline Filhote & Brachyplatystoma filamentosum & Piyuci & 1,9 & 0 \\
\hline Cachorra & Acestrorhynchus falcirostris & Ipico & 0,1 & 0,2 \\
\hline Jacaré tinga & Caiman crocodilus crocodilus & Watwa & 0,5 & 0 \\
\hline Jacundá & Crenicichla Marmorata & Mataiuari & 0,2 & 2,5 \\
\hline Jandiá & Leiarius marmoratus & Kanamuruku & 13,6 & 0,6 \\
\hline Jaraqui & Semaprochilodus spp. & Kronyuku & 4,6 & 0,2 \\
\hline Jejum & Hoplerythrinus unitaeniatu & Xiwiri & 0 & 4 \\
\hline Sarapó & Gymnotiformes & Kaso & 0 & 1,5 \\
\hline Cangatí & Trachycorystes galeatus & Makapa & 0 & 0,1 \\
\hline Mandii & Pimelodus sp. & Warakaka & 1,1 & 2,1 \\
\hline Pacu & Myleus sp. e Mylossoma spp. & Paku katamxiyem & 7,4 & 7,1 \\
\hline Peixe cachorro & Hydrolycus scomberoides & Reyu & 3,1 & 2,2 \\
\hline Peixe cana & Serrasalmidae & Maari & 2,1 & 4,5 \\
\hline Pescada & Cynoscion leiarchus & Rusu & 1,4 & 0,9 \\
\hline Piau & Leporinus friderici & kotîsî & 2,8 & 2,3 \\
\hline Piranha preta & Serrasalmus rhombeus & Poni & 11,1 & 4,1 \\
\hline Pirarara & Phractocephalus hemioliopterus & Kworuymo & 2,3 & 2 \\
\hline Poraquê & Electrophorus electricus & Kaxmi & 0,4 & 0 \\
\hline Sauna & Hemiodus microlepis & Maticara & 0,5 & 0 \\
\hline Surubim & Pseudoplatystoma spp. & Okoropicho & 20,5 & 5,6 \\
\hline Tamuatá & Callichthys callichthy & Okoko & 1 & 14,1 \\
\hline Tipo de cará (Juruparí) & Satanoperca jurupar & Tirpo & 0 & 0,1 \\
\hline Tracajá & Podocnemis unifilis & Twaci & 0,1 & 2,1 \\
\hline Traíra & Hoplias malabaricus & Maxa & 0 & 9,2 \\
\hline Trairão & Hoplias sp. & Aymara & 12,6 & 9,4 \\
\hline Tucunaré & Cichla spp. & Parana & 4 & 12,7 \\
\hline
\end{tabular}

Fonte: Alex Isaac Wai-Wai da Silva e Charles Hanry Faria Junior 


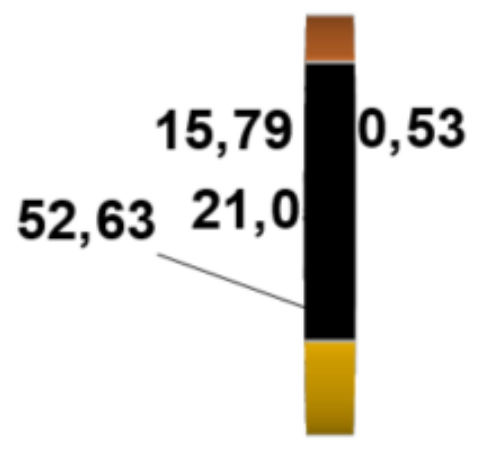

\section{- Amigos Filho \\ Irmão Mulher}

Figura 4. Participantes das pescarias na Aldeia Mapuera. Fonte: Alex Isaac Wai-Wai da Silva e Charles Hanry Faria Junior.

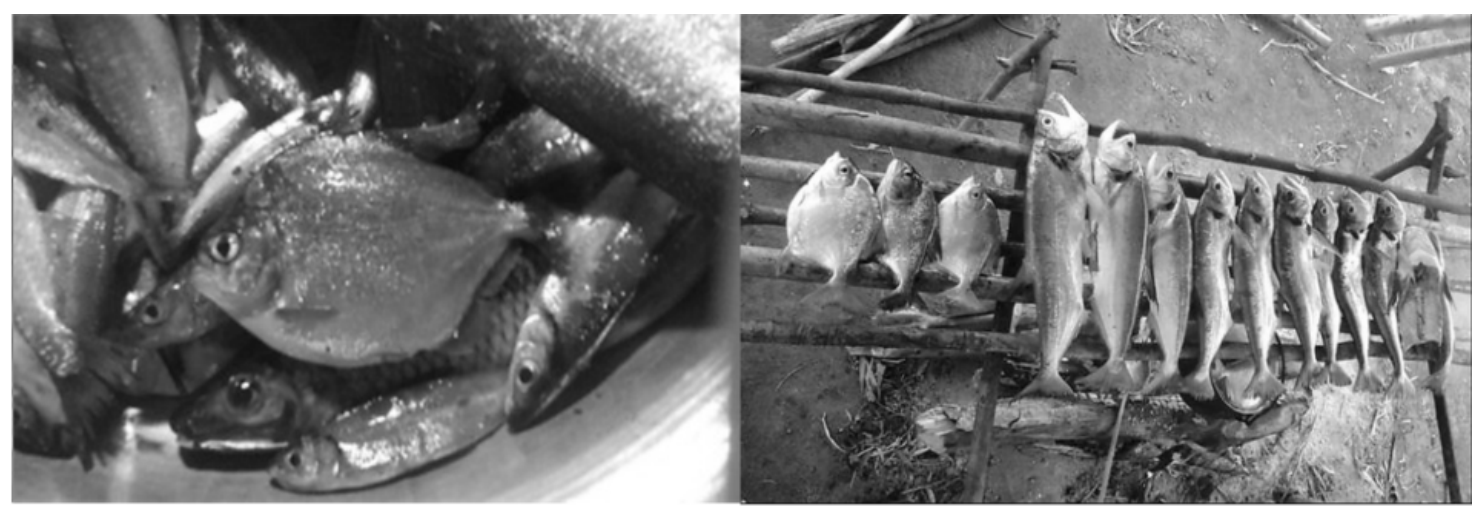

Figura 5. Etnoespécies de peixes utilizadas pelo Wai-Wai. Fonte: Alex Isaac Wai-Wai da Silvar

espalham na mata inundada, o tucunaré, o tracajá e outros peixes ficam difíceis devido ao excesso de água, onde se escondem, porém, é quando esses animais conseguem mais tipos de alimento por causa da subida do nível do rio?

- Para pegar, nos procuramos pescar nos lugares ditos como ideais ou certos de cada índio, onde cada um tem sua estratégia para pegar o tucunaré e o tracajá que procuram um espaço no igapó por causa do alimento, onde também se escondem, ficando difícil de ser pego por causa da abundância (maior área e extensão) do rio.

- Na cheia o jandiá, o pacu, a piranha preta, o surubim e o trairão são encontrados com mais frequência quando saem dos lugares que estão durante o verão e vão para lugares 
Tabela 6. Instrumentos de pesca utilizados pela população indígena da Aldeia Mapuera.

\begin{tabular}{l|l|l}
\hline \multicolumn{1}{c|}{ Instrumentos de pesca } & Nome na língua nativa & $\%$ \\
\hline Arco e flecha & Krapa waywî & 9,67 \\
\hline Caniço & Cecekem & 9,67 \\
\hline Espinhel & Kiwi cimisom & 6,35 \\
\hline Isca artificial & Totkem & 1,10 \\
\hline Linha de pesca com anzol & Xapopo kiwi & 40,88 \\
\hline Malhadeira & Miye & 27,35 \\
\hline Máscara & Ewkanapa kemicitopo & 2,76 \\
\hline Mosquiteiro (rede de arrasto pequena) & Kayrin & 0,28 \\
\hline Timbó & Uumawa & 0,55 \\
\hline Xika (cercado com armadilha) & Xika & 1,38 \\
\hline
\end{tabular}

Fonte: Alex Isaac Wai-Wai da Silva e Charles Hanry Faria Junior

conhecidos, o que facilita a captura.

- Alguns peixes aproveitam para se alimentar com outros peixes e gostam do rio cheio porque na cheia aumenta a fartura de alimentos para suas presas, como frutas de arvores que ficam na beira do rio ou insetos que caem na água, assim, todos os peixes são pescados no lugar onde existem grande quantidade de alimentos. No caso do pacu, ele se encontra durante a chuva porque gosta de se movimentar e alimentar das frutas que caem na água com a chuva e onde tem arvore com frutas tipo araçá.

- A pesca do jandiá fica mais difícil no período no verão porque é uma espécie que gosta de águas profundas e quando o rio está baixo vão para a profundeza do rio, quando o rio começa a encher, começam a sair e sobem o rio para a boca do igarapé em busca de seu alimento, por isso que pescam mais na época da cheia.

- No período do verão o traíra é mais capturada e consumida porque quando o rio baixa, o trairão que estava no igapó fica fácil de pegar com flecha durante a noite.

No caso específico do surubim, apesar de ser a espécie mais explorada, foi frequente o destaque ao aumento da dificuldade de captura independente do período sazonal.

No processo de captura desses recursos os Wai-Wai mencionaram o uso de 10 (dez) instrumentos de pesca, onde a linha de pesca com anzol e a malhadeira se destacam (Tabela 6).

Esse destaque para a linha de pesca e a malhadeira se justificam por serem considerados de fácil aquisição, baixo custo (principalmente a linha de pesca com anzol) e por 


Tabela 7. Consumo per capita e estimado por período sazonal de pescado e alimentos de
origem agrícola e coleta.
\begin{tabular}{l|l|l} 
Consumo & Inverno & Verão \\
\hline Per capita de pescado & $0,43 \pm 0,28$ & $0,31 \pm 0,22$ \\
\hline Per capita de alimentos de origem agrícola e coleta & $0,37 \pm 0,32$ & $0,82 \pm 0,69$ \\
\hline Estimado de pescado no período & 10874,4 & 7984,14 \\
\hline Estimado de alimento de origem agrícola e coleta no período & 9834,14 & 20776,06 \\
\hline
\end{tabular}

Fonte: Alex Isaac Wai-Wai da Silva e Charles Hanry Faria Junior

serem equipamentos de pesca que podem ser utilizados durante todo o ano, enquanto o timbó só é usado no período verão. A linha de pesca é usada na beira do rio, na boca do igarapé e até mesmo no igapó, com tamanho de anzol e isca adequada a cada espécie desejada, uma vez que, os indígenas conhecem os diferentes tipos de peixes que ocorrem nos diferentes habitats dos ambientes aquáticos, seja para refúgio, alimentação ou desova. A malhadeira é utilizada principalmente na boca do igarapé no período cheia, porque os peixes se deslocam com frequência quando o rio está cheio.

Com base nos dados coletados, o consumo per capita anual de produtos derivados da pesca foi em média maior que o da agricultura e coleta no período de inverno, e inferior no verão (Tabela 7).

O maior consumo de peixe na cheia é entendido a partir dos seguintes relatos:

- Os peixes que tinham se deslocado para o rio mais profundo no período de verão, começam a sair e subir no período de rio cheio para lugares diferentes, localizados nas proximidades da Aldeia, isso ajuda na pesca desses peixes.

- No verão fica difícil pegar peixe por causa de alguns animais, tipo onça, garça e outros, que comem e acabam com quase todo peixe dos lagos.

Essa competição natural com os animais é compreendida pelos moradores locais como um dos motivadores da redução, disponibilidade e do consumo, apesar da maior facilidade de captura esperada, como resultado do adensamento dos peixes nos ambientes aquáticos após a descida das águas. Outros motivadores pontuados foram a distância para os locais de pesca durante a seca e a necessidade de trabalhar a roça.

- Os locais de pesca ficam mais distantes da comunidade e é nesse período que se abrem roçados para a plantação, o que demanda tempo para preparar a terra e reduz 
o tempo para a pesca.

A maior disponibilidade para os outros alimentos de origem agrícola e coleta utilizados no verão se explica no seguinte relato.

- É no período de verão que são consumidos mais pela questão de tempo que árvores produzem frutos, porque a maioria das frutas nativas consumidas pela população dão frutos no verão, como bacaba, melancia, abacaxi, banana, batata, cará e outros.

Esses relatos auxiliam a entender os motivos pelos quais o consumo per capita de alimentos é diferenciado nos períodos sazonais, porém, um destaque deve ser dado a tendência de o consumo per capita ser menor de acordo com o número de integrantes do mesmo núcleo familiar (Figura 6), independente do período sazonal, indicando que as famílias maiores tendem a ter dificuldade para suprir a demanda por alimento.
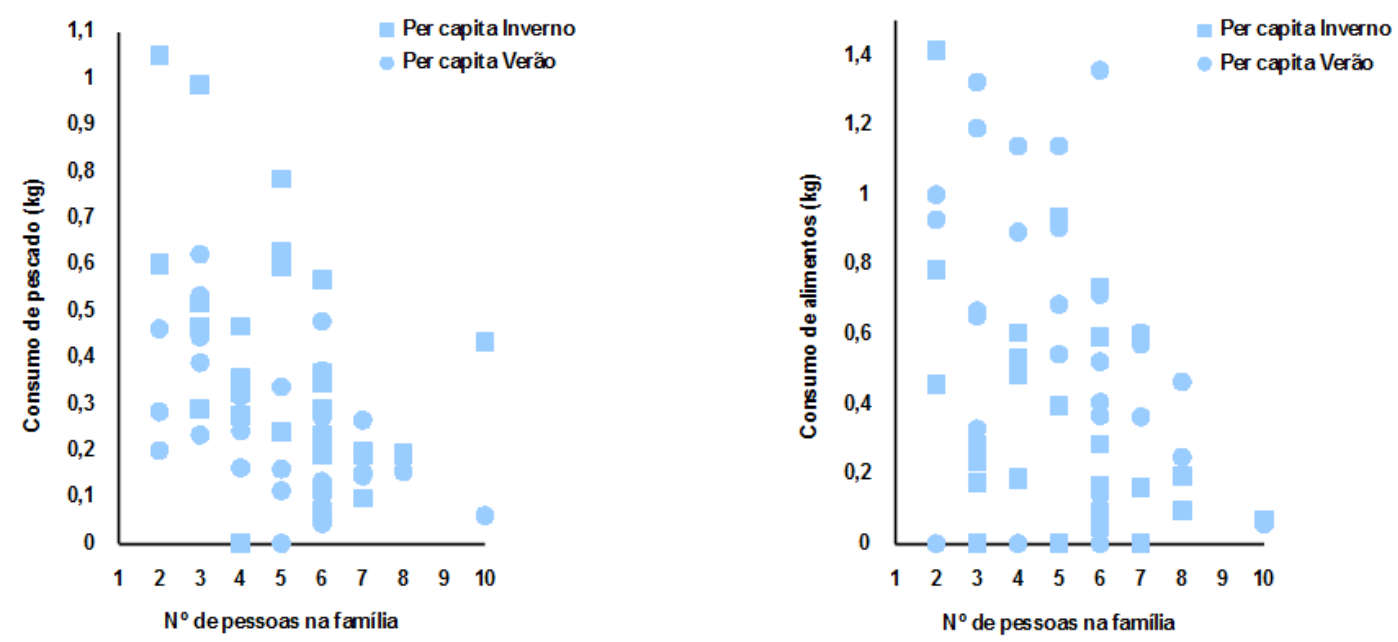

Figura 6. Regressões lineares do consumo per capita de pescado no inverno (CPI) e verão (CPV) e do consumo per capita de alimentos no inverno (CAI) e verão (CAV) de acordo com o número de pessoas na família $\left(N^{\circ}\right.$ p) Wai-Wai. Fonte: Alex Isaac Wai-Wai da Silva e Charles Hanry Faria Junior.

\section{Discussão}

A Aldeia Mapuera em 2012 foi considerada a maior da Região por abrigar o maior número de pessoas (CARDOZO e JUNIOR 2012). Atualmente, com base nas estimativas realizadas no presente estudo, houve um crescimento no quantitativo médio do número de pessoas por núcleo familiar entre os anos de 2011 e 2016, o que resulta em 
um consequente aumento da demanda por alimento dentro dos núcleos familiares e entre os habitantes da Aldeia, apontando para a necessidade da realização de estudos que possam auxiliar na gestão do uso dos recursos naturais no Território Indígena, principalmente sob a ótica do fato histórico, onde a partir da década de 1990 algumas comunidades Wai-Wai como, por exemplo, a Mapuera, grandes demais para sustentar a população devido à escassez de recursos, começaram a passar por uma fase de descentralização (EVELYN, 2010), onde parte da população migrou para outras áreas localizadas dentro da Terra Indígena.

Esse fato poderia indicar um crescimento do quantitativo de crianças, entretanto, na composição dos núcleos familiares predominam os adultos. O fato das crianças serem minoria pode estar relacionado ao contexto matrimonial, que na cultura local, permite que os filhos possam se casar a partir dos 14 anos de idade, quando passa a ser considerados adultos e os homens passam a conviver com a família do sogro após o casamento, para auxiliar nas atividades produtivas voltadas a subsistência, antes de se tornarem independentes e construírem sua própria casa (COIMBRA et al., 2017; PEZZUTI e CHAVES 2009; CARDOZO e JUNIOR 2012).

A caça, a pesca e a coleta de alimentos na floresta são importantes atividades de subsistência que comprovam a dependência que a população indígena têm dos recursos naturais e do uso harmônico desses (SILVA, 2015; RADAELLI, 2017), além disso, para a sua obtenção e preparo, existe uma divisão de tarefas segundo o gênero, podendo ocorrer variações de um povo para outro (SILVA, 2015), onde os homens caçam e pescam e as mulheres realizam as atividades coletoras (quando acompanham seu marido) e os trabalhos agrícolas (RADAELLI, 2017), portanto, o maior quantitativo de mulheres observado nos núcleos familiares, auxilia a entender essa maior média de pessoas envolvidas na agricultura.

Segundo Evelyn (2010), Cardozo e Junior (2012), Crepaldi (2012), Neves (2012), Silva (2015) e Radaelli (2017), as famílias indígenas organizam suas atividades por gênero e idade dos seus integrantes. No caso dos homens, os adultos pescam, caçam, derrubam roça, fazem canoas, constroem casas, coletam materiais para a confecção de artefatos, as crianças podem ajudar o pai como parte do seu aprendizado e a partir de 6 
anos podem participar de algumas atividades, entre elas a pesca. As mulheres adultas têm a função do cultivo de roças, carregar água, cozinhar e servir a família, as crianças ajudam no preparo dos alimentos (caça, peixe, bebidas, beiju) e a partir dos 6 anos cuidam dos irmãos pequenos enquanto mãe e irmãs mais velhas preparam seus alimentos. As mulheres também fazem artefatos de cerâmica, raladores para a mandioca, tangas e colares de sementes, entre outros (LEITE, 2007; GAZETA DO OESTE, 2008; ARAÚJO e TORRES 2010; SILVA, 2015).

Na Aldeia Mapuera, cada família é responsável pelas suas atividades, porém, atividades como o roçado podem ser realizadas com ajuda dos maridos e filhos ou envolver outros núcleos familiares como cunhados. Para os homens ter irmãs é importante, pois, implica em ter mais ajuda. No caso da participação das crianças, os trabalhos que executam além de cuidar do irmão mais novo, pode se estender a pegar e cortar mandioca, buscar água ou pescar, de acordo com a sua capacidade e força (SILVA, 2015).

Os produtos derivados da agricultura tradicional indígena relacionados não diferem dos apresentados nos estudos realizados de Evelyn (2010) e Cardozo e Junior (2012), onde destacam que entre os cultivares Wai-Wai constam: abacaxi, abóbora, banana (diversas espécies), cana-de-açúcar, mamão, tubérculos como cará e batatas (diferentes tipos) e, sobretudo, a macaxeira, das quais extraem o tucupi, a goma e produzem o beiju, as farinhas e bebidas. A fabricação e uso de bebidas fermentadas, como o caxirí, fazem parte da cultura e tem importante papel social das diferentes sociedades indígenas (SOUZA et al., 2005; SOUZA et al., 2010). De acordo com o conhecimento tradicional, são mais consumidos no verão porque é nesse tempo que as árvores produzem frutos.

Os produtos derivados da coleta como os cajus silvestres, açaí, buriti, bacaba, pupunha e a castanha são de uso comum de populações indígenas da região Norte, podendo receber outras denominações de acordo com a língua da etnia estudada (LEITE, 2007; QUEIROZ, 2015; SILVA, 2015).

Os produtos da caça são exclusivos para subsistência familiar e utilizados para a alimentação, confecção de artesanatos e uso medicinal, entretanto, podem ocorrer divisão da produção entre parceiros na caça, parentes e vizinhos. É uma atividade realizada durante todo o ano de acordo com a necessidade das famílias, porém, tende a 
uma menor intensidade no período do verão devido a dedicação das famílias aos trabaIhos nas roças e pode ser realizada individualmente ou de forma coletiva em momentos de festividades devido a necessidade de obter maior quantidade de alimento para toda a comunidade (LEITE, 2007; GAZETA DO OESTE, 2008; PEZZUTI e CHAVES 2009; CARDOZO e JUNIOR 2012). De acordo com Pezzuti e Chaves (2009), essa atividade tem maior resultado produtivo em aldeias novas, ocorrendo uma redução da abundância na proximidade com a continuidade da caça ao longo dos anos, realidade observada na Aldeia Mapuera por Cardozo e Junior (2012), o que pode resultar na busca da caça em localidades mais distantes, em alguns casos, em território de outra Aldeia e causar descontentamentos e tensão devido a disputa por alimento.

O que auxilia a entender o porquê um alimento é mais utilizado ou citado como mais importante que o outro é a possibilidade do seu uso individual ou associado a outro item alimentar, como no caso da banana, batata, abacaxi, beiju, vinho de bacaba ou buriti e a farinha, que são consumidos com peixe, carne de caça ou no preparo e acompanhamento de outros alimentos, como os mingaus.

No contexto da participação dos integrantes dos núcleos familiares nas atividades produtivas, o que justifica a participação de poucos integrantes na pesca, segundo o conhecimento tradicional dos entrevistados é o fato de "muitos participantes atrapalharem a pesca devido a movimentação e o barulho, que são percebidos pelos peixes, que se escondem, dificultando a pesca”, porém, assim como no caso da caça, a pesca pode ser realizada coletivamente em momentos de momentos de festividades.

Outro motivador é que em alguns casos os pescadores não se deslocam somente para pescar, assim, na ida para os locais de pesca ou na volta para casa, podem realizar a retirada de bacaba ou se a família tiver uma roça no caminho, passam e apanham algumas frutas como banana, abacaxi, batata, entre outros.

O papel da participação da mulher na pesca é a de auxiliar o homem enquanto ele realiza a captura, auxiliam também na retirada dos peixes da malhadeira, no remar e no manuseio do peixe na canoa, além de, ao chegar em casa, ela ou suas filhas tratam e preparam os peixes para o consumo familiar. O homem antes mesmo de sair de casa para pescar, prepara o material de pesca: tipo anzol, malhadeira e outros aparelhos de 
pesca e se for realizar a pesca com flecha, faz arco e a flecha um dia antes de ir pescar. Ao sair da aldeia o homem é quem rema até chegar no local de pesca e a partir de lá, é a mulher que rema, assim compartilham o trabalho e resultado da pesca.

Apesar de se observar um diferencial na captura de peixes entre os períodos sazonais (GRUPIONI e ANDRADE 2015; JUNIOR et al., 2015; COIMBRA et al., 2017), os pescadores indígenas auxiliam no entendimento desse diferencial observado (maior consumo no inverno que no verão), que contraria a tendência de maior produção pesqueira regional e consumo no período de verão (PETRERE, 1992; SOUZA et al., 2015, BRELAZ et al., 2018), quando afirmam que o efeito das capturas sobre o consumo de algumas etnoespécies é mais acentuado no período de cheia, porque, apesar dos tucunarés, carás, tracajás e outras espécies se tronarem mais difíceis de captura, a pesca de jandiá é mais fácil nesse período, "porque gostam de águas profundas e no verão se escondem", se refugiando e quando o rio começa a encher, iniciam processo migratório e "sobem o rio para a boca do igarapé em busca de seu alimento, por isso que a pescam mais na época da cheia”. A partir do conhecimento acumulado contornam as dificuldades de pescar em um ambiente mais aberto ao conhecer a disponibilidade de frutos, sementes e insetos pressentes nas áreas alagadas, aproveitando os hábitos alimentares do tracajá, pacu, tucunaré, piranha preta, trairão e outros peixes, além delimitar individualmente as áreas de pesca "ideais ou certas" como estratégia para reduzir a dificuldade de captura.

Esses relatos indicam de um lado o elevado conhecimento do efeito da variação no nível das águas sobre a vegetação, bem como da ecologia de algumas etnoespécies de peixes e outros organismos aquáticos explorados, e de outro, o entendimento da sazonalidade como fator na dispersão e concentração dos peixes no período de inverno e verão respectivamente (PEZZUTI e CHAVES 2009; CARDOZO e JUNIOR 2012; BRAGA e REBÊLO 2014; COIMBRA et al., 2017). Além disso, conhecem certos pontos no igarapé, igapó e rio, onde determinadas espécies de peixe são encontradas ou estão de passagem, de acordo com os saberes locais transmitidos por gerações (RIBEIRO, 1995; SILVA, 2011). Nesse processo o conhecimento é "divido" (compartilhado), quando os índios mais velhos repassam seus conhecimentos aos mais novos e no caso das demais atividades, das mães para as filhas ao longo dos ensinamentos das práticas culturais (CREPALDI, 2012). 
No caso dos principais aparelhos de pesca utilizados, o destaque para a linha de pesca e a malhadeira se justificam por serem considerados de fácil aquisição, baixo custo (principalmente a linha de pesca com anzol), sua praticidade e facilidade de uso e por serem equipamentos de pesca que podem ser utilizados durante todo o ano (BRELAZ et al., 2018). Os pescadores da Aldeia Mapuera utilizam a linha de pesca na beira do rio, na boca do igarapé e até mesmo no igapó, com tamanho de anzol e isca adequada a cada espécie desejada, por conhecerem os diferentes tipos de peixes que ocorrem nos diferentes habitats aquáticos.

De acordo com o conhecimento dos entrevistados, a malhadeira é utilizada principalmente na boca do igarapé no período cheia, porque os "peixes se deslocam com frequência quando o rio está cheio". Apesar de ser considerado um aparelho de captura versátil, de fácil manuseio, permitir a captura de várias espécies de peixes de formas e tamanho diferentes, dependendo das características de malha, além de possibilitar o uso de outros aparelhos de captura enquanto a malhadeira está armada em um determinado local escolhido para a pesca (FERNANDES et al., 2009; BRELAZ et al., 2018), foi apontada por muitos pescadores indígenas como prejudicial ao estoque pesqueiro devida a possibilidade de captura de muitos peixes em pouco tempo, reduzindo assim a quantidade de peixes em alguns locais, característica destacada nos estudos de Cardozo e Junior (2012) e relatado na pesca de subsistência e comercial na Amazônia (LIMA et al., 2012).

Como observado, as atividades do povo Wai-Wai relacionadas a produção, coleta e consumo de alimento se alteram durante as épocas de seca (verão) e a época chuvosa (inverno), onde a primeira é farta em comida e a segunda marcada pelos recursos mais escassos, corroborando com os resultados obtidos por Evelyn (2010), Rocco (2014) e Cardozo e Junior (2012). Porém, além do efeito sazonal, o consumo de pescado e de outros alimentos derivados da caça, cultivo ou coleta variam de acordo com o número de integrantes do núcleo familiar e a idade destes (segundo relatos, crianças a partir de 2 anos passam a se alimentar da dieta dos adultos, de acordo com sua necessidade).

Com base no consumo estimado para os 155 integrantes das 32 famílias entrevistadas em cada período sazonal, se estima que os 977 habitantes da Aldeia Mapuera 
quantificados no estudo de Cardozo e Junior (2012) demandariam anualmente 118.869 kg de pescado e $192.943 \mathrm{~kg}$ de alimentos de origem agrícola e coleta. Se a população no momento da coleta de dados fosse de 2.000 habitantes (estimativa do co-autor), essa demanda seria da ordem de $243.336 \mathrm{~kg}$ de pescado e $394.970 \mathrm{~kg}$ de alimentos de origem agrícola e coleta, o que representa um aumento na demanda total por alimentos superior a $200,0 \%$ de 2011 a 2016.

Na ótica da importância e alternância os itens alimentares entre períodos sazonais, merece destaque o fato do pescado representar $40,37 \%$ da demanda anual de alimentos e ser um importante item alimentar para a população local, principalmente no período de inverno, momento descrito como de escassez dos recursos naturais (LEITE, 2007; SCHULER ZEA, 2010)

A análise do consumo per capita de pescado e outros alimentos em função do quantitativo de pessoas pertencentes ao mesmo núcleo familiar, apesar das equações não possuírem estatisticamente coeficientes robustos $(>0,5)$, mostram que o número de integrantes nos núcleos familiares interfere na quantidade de alimentos consumido por cada indivíduo, o que pode influenciar negativamente a condição nutricional dos integrantes de famílias mais numerosas. Um alerta para as possíveis dificuldades no provimento de um quantitativo de alimento suficiente para satisfazer as necessidades das famílias, uma vez que se têm relatos, no caso da exploração dos recursos pesqueiros, da maior dificuldade nas capturas como resultado da quantidade menor de peixes nos ambientes em decorrência da maior pressão de pesca para atender o crescimento da população na Aldeia e o consequente aumento da demanda. Esse relato encontra respaldo no trabaIho de Cardozo e Junior (2012), que mostraram a preocupação da população quanto a disponibilidade de peixes para os próximos anos, demonstrando interesse em buscar o manejo dos recursos pesqueiros nas áreas de pesca pertencentes ao território indígena.

Essas características mostram a importância do peixe e outros alimentos na dieta da população indígenas, característica básica por viverem no regime de dependência do mundo natural, de seus ciclos e de seus produtos, fundamentais para a produção e reprodução de seu modo de vida (DIEGUES, 2007; REBELO e BRAGA 2014). 


\section{Conclusão}

A população indígena que reside na Aldeia Mapuera obtém da agricultura, coleta, caça e pesca suas principais fontes de alimento, mantendo um modo de vida ligado ao uso coletivo dos recursos naturais e prática agrícola de subsistência, onde as atividades são culturalmente desenvolvidas segundo a divisão de tarefas entre gêneros e faixa etária dos integrantes do núcleo familiar.

A catalogação de 30 etnoespécies de peixes (que podem resultar em mais de 50 espécies), uma de crustáceos, uma de quelônios, uma de crocodilianos, 40 itens derivados do cultivo, coleta e troca, além dos 16 animais relacionados como caça, exemplificam a diversidade de itens utilizados, porém, podem representar uma subestimativa da diversidade dos itens utilizados pela população local, estimada em 2.000 pessoas, o que aponta para a necessidade de continuidade de estudos nessa temática, que possibilitem compreender a real diversidade dos itens utilizados.

Apesar de consumidos ao longo de todo o ano, o quantitativo obtido e produzido, a demanda individual e associado a outros itens alimentares, bem como a importância desses itens, se alternam entre os períodos de inverno e verão, como resultado das condições ambientais e da sazonalidade produtiva.

O ciclo agrícola se inicia no verão com a abertura dos roçados, queima e plantio, além de ser o período destacado pelos moradores da Aldeia como o momento em que as árvores produzem seus frutos. Nesse período as caçadas tendem a uma menor intensidade devido a dedicação das famílias aos trabalhos nas roças.

O resultado da pesca no contexto amazônico, tende a ser mais produtivo no período de verão, como resultado da redução dos ambientes aquáticos, favorecendo as capturas devido a concentração de peixes e demais organismos, ocorrendo o inverso no inverno, quando os recursos pesqueiros se dispersam devido a subida do nível das águas e o transbordamento lateral dos ambientes aquáticos, ficando menos acessíveis e, portanto, menos vulneráveis a captura. Entretanto, essa atividade resultou em um maior volume consumido e maior índice per capita no inverno, enquanto os produtos derivados da agricultura, coleta e caça, se destacaram no verão.

Essa diversidade de itens bem como a produção diferenciada na pesca é resultado 
do conhecimento transmitido entre gerações, fortalecido nas práticas cotidianas de cada indivíduo, que mantém profunda interação com o meio em que vive e explora, passando a conhecer os melhores período para o plantio, coleta de frutos, locais de ocorrência de caças e a interpretar o comportamento ecológico e alimentar dos organismos aquáticos, em destaque os peixes, para saber as espécies mais acessíveis e vulneráveis e mapear mentalmente os melhores locais de captura a cada período sazonal.

Apesar da população local possuir esse marcante conhecimento tradicional na utilização dos recursos naturais e aproveitar uma grande diversidade de itens alimentares, o crescimento da população da Aldeia Mapuera vem inferindo crescentes dificuldades no compartilhamento dos recursos, com relatos históricos da necessidade de divisão da população para a formação de novas aldeias em locais menos explorados, como estratégia para garantir a subsistência e qualidade de vida coletiva.

Essa dificuldade na obtenção e compartilhamento de alimento se evidenciou internamente nos núcleos familiares, onde foi constatada a tendência de um menor consumo per capita de alimento para indivíduos pertencentes a núcleos familiares maiores, demandando entendimento dos fatores explicativos (exógenos e endógenos aos núcleos familiares) desse fenômeno, uma vez que a maior parcela da população estudada $(67,10 \%)$ é composta por adultos e, portanto, aptos a produzir alimentos a partir das práticas produtivas comuns na Aldeia Mapuera, assim, o que se esperaria é maior quantidade de alimentos para familiar com maior número de pessoas.

Essa realidade, quando associada ao aumento populacional e a maior pressão sobre os recursos naturais, reforçam a necessidade de estudos direcionados a influência do crescimento populacional sobre o uso dos recursos naturais, bem como do efeito da redução do consumo sobre a condição nutricional da população local e da integridade da Terra Indígena, para que possa assimilar de forma sustentável a dispersão e formação de novas Aldeias, permitindo a manutenção do modo de vida e das práticas culturais Wai-Wai, além de construir referencial para as demais populações indígenas distribuídas no território Brasileiro. 


\section{Agradecimentos}

Agradecemos a colaboração das famílias Wai-Wai entrevistadas e a recepção dada ao jovem Wai-Wai co-autor do presente trabalho, que utilizou a oportunidade que tem na Universidade Federal do Oeste do Pará, para produzir informações visando o benefício de seu povo e seu crescimento pessoal.

\section{Referências}

ADMS, C.; MURRIETA, R. S. S.; SANCHES, R. A. 2005. Agricultura e alimentação em populações ribeirinhas das várzeas do Amazonas: novas perspectivas. Ambiente \& Sociedade - Vol. VIII n'. 1 jan./jun.

ARAÚJO, W. R. M. e TORRES, I. C. 2010. TRABALHO E GÊNERO NA COMUNIDADE SATERÉ-MAWÉ I'NHAÃ-BÉ EM MANAUS, AM. Fazendo Gênero 9. Diásporas, Diversidades, Deslocamentos. 23 a 26 de agosto de 2010.

BIDONE, E. D.; SOUZA, T. M. C.; MASCARENHAS, A. F. S. e RODRIGUES, R. M. 1995. Monitoramento de Águas e Peixes na Bacia do Tapajós. Belém: Secretaria de Estado de Indústria, Comércio e Mineração - Seicom/Governo do Estado do Pará.

BRABO, E. S.; SANTOS, E. C. O.; JESUS, I. M.; MASCARENHAS, A. F. e FAIAL, K. F. 1999. Níveis de mercúrio em peixes consumidos pela comunidade indígena de Sai Cinza na Reserva Munduruku, Município de Jacareacanga, Estado do Pará, Brasil. Cadernos de Saúde Pública, v. 15:p.325-331.

BRAGA, T. M. P. e REBÊLO, G. H. 2014. Conhecimento tradicional dos pescadores do baixo rio Juruá: aspectos relacionados aos hábitos alimentares dos peixes. INTERCIENCIA SEPTEMBER 2014, VOL. $39 \mathrm{~N}^{\circ} 9$.

BRELAZ, R. L; FARIA-JUNIOR, C. H. e RIBEIRO, F. R. V. 2018. Caracterização da atividade pesqueira na comunidade Vila Flexal do município de Óbidos, Pará, Brasil: subsídios para gestão dos recursos. Scientia Amazonia, v. 7, n.1, 134-155, 2018.

CARDOZO, I. B. e JUNIOR, I. C. V. 2012. Etnozoneamento da porção paraense das terras indígenas Trombetas-Mapuera e Nhamundá-Mapuera / Ivaneide Bandeira Cardozo, Israel Correa do Vale Junior, org. -Porto Velho - RO: EDUFRO. 200p. il.

CANESQUI, A. M. e GARCIA, R. M. D. 2005. Uma introdução à reflexão sobre a abordagem sociocultural da alimentação. Antropologia e nutrição: um diálogo possível. Coleção Antropologia e Saúde. Rio de Janeiro: Editora FIOCRUZ. 306p.

COIMBRA, A. B.; TERRA, A. K.; MAZUREK, R. R. S.; PEREIRA, H. S.; BELTRÃO, H. e SOUSA, R. G. C. 2017. Atividade pesqueira dos índios mura no lago Ayapuá, baixo rio Purus, Amazonas, Brasil. Revista Desafios - v. 04, n. 1.

CREPALDI, G. B. 2012. Alimentação indígena em mato grosso: educação ambiental e sustentabilidade entre etnias de estudantes da faculdade indígena intercultural. Dissertação apresentada à Universidade do Estado de Mato Grosso como parte das exigências 
do Programa de Pós-Graduação em Ciências Ambientais para obtenção do Título de Mestre. CÁCERES, MATO GROSSO, BRASIL.

DIEGUES, A. C. 2007. Água e cultura nas populações tradicionais brasileiras. I Encontro Internacional: Governança da Água, São Paulo, novembro, 2007.

EVELYN, S. Z. 2010. (TRANS)FORMAÇÕES WAI-WAI. Roraima: Homem, Ambiente e Ecologia.

FERNANDES, V. L. A.; VICENTINI, R. N. e BATISTA, V. S. 2009. Caracterização do uso de malhadeiras pela frota pesqueira que desembarca em Manaus e Manacapuru, Amazonas. Acta Amazonica, v. 39, n. 2, p. 405-414.

GARNELO, L., DINIZ, L., SAMPAIO, S. e SILVA, A. Ambiente, saúde e estratégias de territorialização entre os índios Baniwa do Alto Rio Negro. Campo Grande - MS. Tellus, 2010.

GAZETA DO OESTE, 2008. Índios resistem e mantêm identidade. Oriximiná é pioneira em atenção a índios cultural. URUÁ-TAPERA. Ano XVI No 156, ABRIL 2008. Disponível em <www.uruatapera.com $>$.

GOULDING, M. 2010. Amazonian fisheries. p. 189 - 210. In: MORAN, E. F. (ed.). The dilemma of Amazonian development, Westview Press, Boulder, Colorado, n. 18, p. 39-63.

GRUPIONI, D. F. e ANDRADE L. M. M. 2015. Entre Águas Bravas e Mansas, índios \& quilombolas em Oriximiná / organização Denise Fajardo Grupioni, Lúcia M.M. de Andrade. - São Paulo: Comissão Pró-Índio de São Paulo: lepé.

ISA, 1991. Índios Wai-Wai na Aliança Francesa. O Estado de Minas, 05/05/1991. CEDI - Povos indígenas do Brasil. Acero ISA, 1991.

JUNIOR, J. R. C.; CARVALHO, J. R. S. S.; SILVA, T. R. M.; BARROS, F. B. e NAKAYAMA. L. 2015. Entre Mex E Pỳnỳre: Peixe Bom Para Comer, Peixe Bom Para Viver Na Terra Indígena Trincheira Bacajá - PA, Povo Xikrin. Rev. FSA, Teresina, v. 12, n. 2, art. 4, p. 58-77, Mar./Abr.

KATZ, E. 2008. Alimentação indígena na América Latina: Comida invisível, comida de pobres ou patrimônio culinário? "Trabalho apresentado na 26a". Reunião Brasileira de Antropologia, realizada entre os dias 01 e 04 de junho, Porto Seguro, Bahia, Brasil."

KURO, R. 2003. Avaliação da contaminação por mercúrio em peixes do Alto Pantanal Mato Grosso - Brasil. São Paulo. Dissertação de mestrado - Faculdade de Saúde Pública da Universidade de São Paulo. 112p.

LEITE, M. S. 2007. Transformação e persistência: antropologia da alimentação e nutrição em uma sociedade indígena amazônica [online]. Rio de Janeiro: Editora FIOCRUZ. 239 p. ISBN 978-85-7541137-7. Available from SciELO Books <http://books.scielo.org>.

LIMA, M. A. L; DORIA, C. R. C. e FREITAS, C. E. C. 2012. Pescarias artesanais em comunidades ribeirinhas na Amazônia Brasileira: perfil socioeconômico, conflitos e cenário da atividade. Ambiente \& Sociedade, v. 15, n. 2, p. 73-90.

LOPES, M. L. B.; COSTA, P. A.; SANTOS, J. S. B.; CUNHA, S. G. T. e SANTOS, M. A. S. 2015. Mercado e dinâmica espacial da cadeia produtiva da pesca e aqüicultura na Amazônia. Estudos Setoriais, 7. Banco da Amazônia, Belém - Pará. 51p. 
MILLER, R. P.; WANDELLI, E. V. e GRENAND, P. 1989. CONHECIMENTO E UTILIZAÇÂO DA FLORESTA PELOS ÍNDIOS WAIMIRI-ATROARI DO RIO CAMANAU - AMAZONAS. Acta bol. bras. 3(2): Suplemento.

MURRIETA, R. S. S. 2001. Dialética do sabor: alimentação, ecologia e vida cotidiana em comunidades ribeirinhas da llha de Ituqui, Baixo Amazonas, Pará. REVISTA DE ANTROPOLOGIA, SÃO PAULO, USP. V. $44 \mathrm{n}^{\circ} 2$.

NEVES, S. F. 2012. CORPO FORTE, DANÇA ALEGRE: Para uma antropologia da dança entre os Wai-Wai. Trabalho de dissertação apresentado ao Programa de Pós-Graduação em Antropologia Social - PPGAS para avaliação da Banca Examinadora, como requisito final para a obtenção do título de Mestre em Antropologia Social do Museu Amazônico/Universidade Federal do Amazonas. 103p.

OVIEDO, A. F. P. 2017. Pescadores de Manoel Urbano e a construção de um território de pesca numa perspectiva etnoecológica. Revista Ciências da Sociedade (RCS), Vol. 1, n. 2, p.103-126, Jul/Dez.

PETRERE, JR. M. 1992. As comunidades humanas ribeirinhas da Amazônia e suas transformações sociais. 31-68 p. In: DIÉGUES, A.C. (ed.) Populações humanas, rios e mares da Amazônia. Anais do IV Encontro de Ciências Sociais e o Mar no Brasil, São Paulo.

PEZZUTI, J. e CHAVES, R. P. 2009. Etnografia e manejo dos recursos naturais pelos índios Deni, Amazonas, Brasil. Acta Amazonica, v.39, n.1, p. 121-138.

PIROSKI, N. M.; CASTRO, A. C. L.; PINHEIRO, C.U B.. A prática da pesca entre grupos indígenas das bacias dos rios Pindaré e Turiaçú, no Estado do maranhão, Nordeste do Brasil. Boletim do laboratório de Hidrobiologia, 16:67-74, 2003.

QUEIROZ, R. C. 2015. Cosmologia e história Wai-Wai e Katxuyana: sobre os movimentos de fusão e dispersão dos povos (Yana). Entre Águas Bravas e Mansas, índios \& quilombolas em Oriximiná / organização Denise Fajardo Grupioni, Lúcia M.M. de Andrade. São Paulo: Comissão Pró-Índio de São Paulo: lepé.

RADAELLI, E. R. P. 2017. Alimentação cultura. Departamento de Nutrição da Faculdade de Ciências da Saúde da Universidade de Brasília (FS/UnB) e a Área Técnica de Alimentação e Nutrição do Departamento de Atenção Básica da Secretaria de Política de Saúde do Ministério da Saúde (DAB/SPS/MS). Disponível em <http://bvsms.saude.gov.br/bvs/publicacoes/alimentacao_cultura.pdf>.

RIBEIRO, B. G. 1995. Os índios das águas pretas: modo de produção equipamento produtivo. Companhia das Letras: Editora da Universidade de São Paulo.

ROCCO, R. G. 2014. O Sistema Jurídico dos Índios Wai Wai e a imprescindibilidade da Jusdiversidade no Brasil. GT 31 - Projetos de desenvolvimento e direitos territoriais das populações tradicionais: alternativas de desenvolvimento. $39^{\circ}$ Encontro Anual da ANPOCS.

SÁ, A. L.; HERCULANO, A. M; PINHEIRO, M. C.; SILVEIRA, L. C. L.; DO NASCIMENTO, J. L. M. e CRESPO-LÓPEZ, M. E. 2006..Exposição humana ao mercúrio na Região Oeste do Estado do Pará. Revista Paraense de Medicina V.20 (1) janeiro - março. 7p. 
SANTOS, E. C. O., CÂMARA, V. M., BRABO, E.S., LOUREIRO, E.C.B., JESUS, I.M., FAYAL, K. e SAGICA, F. 2003. Avaliação dos níveis de exposição ao mercúrio entre índios Pakaanóva, Amazônia, Brasil. Cad. Saúde Pública, Rio de Janeiro, 19(1):199206, jan-fev. 8p.

SCHULER ZEA, E. 2010. (TRANS)FORMAÇÕES WAIWAI. Roraima: Homem, Ambiente e Ecologia.

SILVA, C. M. 2015. A imagem do índio amazônico: a sociodiversidade indígena e os principais preconceitos ontem e hoje. Fórum Nacional dos Conselhos Estaduais de Educação. XLIV Plenária Nacional do Fórum dos Conselhos Estaduais de Educação FNCE. Sistematização de Experiências dos Conselhos Estaduais de Educação.

SILVA, R. E.; FERREIRA, R. R. 2018. Construção de Acordos de Pesca e Políticas Públicas para gestão de recursos pesqueiros na Região de Santarém, Pará (1990-2004). O Social em Questão - Ano XXI - nº 41 - Mai a Ago/2018.

SMITH, N. 1979. A pesca no Rio Amazonas. INPA/CNPq, Manaus. 154 pp.

SOUZA, J. A.; OLIVEIRA, M. e KOHATSU, M. 2005. O uso de bebidas alcoólicas nas sociedades indígenas: algumas reflexões sobre os Kaingáng da bacia do rio Tibagi, Paraná. Epidemiologia e saúde dos povos indígenas no Brasil / Organizado por Carlos E. A. Coimbra Jr. Rio de Janeiro: Ed. FIOCRUZ IABRASCO.

SOUZA, M. L. P.; DESLANDES, S. F. e GARNELO, L. 2010. Modos de vida e modos de beber de jovens indígenas em um contexto de transformações. Ciência \& Saúde Coletiva, 15(3):709-716.

VAN VELTHEM, L. H. 1990. Os Wayana, as águas, os peixes e a pesca. Bol. Mus. Paraense Emilio Goeldi, Série Antropológica, 6 (1).

VERÍSSIMO, J. 1995. A pesca na Amazônia. Livraria Clássica Alves, Rio de Janeiro. $206 \mathrm{p}$.

ZAR, J. H. 1999.; Biostatystical Analisys. 4ed. Ed.Prentice-Hall. 661p. 